\title{
PENGARUH DUKUNGAN MANAJEMEN PUNCAK DAN PENGETAHUAN MANAJER TERHADAP EFEKTIVITAS SISTEM INFORMASI AKUNTANSI PADA PERUSAHAAN RETAIL DI MANADO \\ (Pada PT. Ace Hardware Tbk, PT. Informa Furnishings dan Toys Kingdom)
}

\author{
Teza Christy Pontonuwu ${ }^{1}$, Inggriani Elim ${ }^{2}$, I Gede Suwetja ${ }^{3}$ \\ 1,2,3 Jurusan Akuntansi, Fakultas Ekonomi dan Bisnis, Universitas Sam Ratulangi, Jl. Kampus Bahu, Manado, \\ 95115, Indonesia
}

Email: Tezapontonuwu@gmail.com

\begin{abstract}
Accounting information system is very important part to improve organizational efficiency and support competitiveness by providing financial and accounting information for the company. The system can be said to be effective if the system is able to produce information that is acceptable and able to meet the expectations of information in a timely, accurate, and reliable. This study aims to examine the effect of top management support and knowledge manager on the effectiveness of accounting information systems. The population in this study is retail companies located in Manado. This study used Purposive sampling technique, obtained 42 people as respondents with questionnaire as the research instrument. This study used primary data that is the answer of the respondents tabulated and processed using SPSS software (Statistic Product and Service Solution) version 22. Data analysis was performed with multiple linear regression analysis. The result of this study showed that top management support and knowledge manager simultaneously affect the effectiveness of accounting information system. Top management support as partially has a positive effect on the effectiveness of accounting information system meanwhile knowledge manager has no effect on the effectiveness of accounting information system.
\end{abstract}

Keywords: Top Management Support, Knowledge Manager, Effectiveness Of Accounting Information System

\section{PENDAHULUAN}

Persaingan yang ketat menuntut suatu perusahaan untuk mampu bersaing dan mempertahankan kelangsungan hidup perusahaan, terutama dalam era globalisasi ini. Kecanggihan teknologi di masa kini memiliki perkembangan yang pesat bahkan mampu menghasilkan beraneka ragam teknologi sistem yang dirancang untuk membantu pekerjaan manusia dalam menghasilkan kualitas informasi terbaik. Kenanekaragaman teknologi tersebut memberikan kemudahan bagi para pengguna teknologi dalam implementasi. Perusahaan yang memiliki teknologi informasi yang canggih (terkomputerisasi dan terintegrasi) dan didukung oleh aplikasi pendukung teknologi modern dapat memberikan dampak positif bagi kelangsungan kinerja perusahaan dengan menghasilkan laporan keuangan yang tepat waktu, akurat dan dapat dipercaya.

Sistem informasi akuntansi merupakan sistem yang menyediakan informasi akuntansi dan keuangan beserta informasi lainnya yang diperoleh dari proses rutin transaksi akuntansi (TMBooks, 2014 : 2). Efektivitas sistem informasi akuntansi sangat tergantung pada keberhasilan kinerja antara sistem , pemakai (user), dan sponsor. Faktor - faktor penting yang dapat mempengaruhi efektivitas sistem informasi akuntansi diharapkan dapat memberikan pengaruh posistif yang dapat menunjukan tingkat keberhasilan sistem dalam menjalankan fungsinya (Kadek Indah \& I Gusti AS, 2014). 
Dukungan manajemen puncak sangat penting dalam implementasi suatu sistem, terutama dalam situasi inovasi dikarenakan adanya kekuasaan manajer terkait sumber daya yang diperlukan, tujuan dan inisiatif strategi yang direncanakan apabila manajer mendukung sepenuhnya dalam implementasi sistem baru (Fatimah, 2013).

Pengetahuan manajer akuntansi terhadap sistem informasi juga merupakan faktor yang tidak kalah penting dalam aplikasi serta pengembangan sistem informasi akuntansi . Kompleknya sistem informasi akuntansi, luasnya lingkup transaksi akuntansi yang mencakup semua bagian perusahaan, dan adanya banyak prosedur dalam proses sistem informasi akuntansi mulai dari terjadinya transaksi sampai dihasilkannya laporan keuangan, menuntut seorang manajer memiliki kapasitas yang memadai untuk melakukan evaluasi atas trouble system dan kemudian mengambil tindakan yang cukup untuk mengatasi permasalahan tersebut, sehingga tidak berdampak terhadap siklus sistem informasi akuntansi secara keseluruhan (Fadhilah, 2013).

Penelitian ini menggunakan perusahaan retail yang ada di Manado sebagai objek yang akan diteliti yaitu pada PT. Ace Hardware Tbk, PT. Informa Furnishings dan Toys Kingdom. Alasan dilakukan pada perusahaan tersebut adalah karena tiga perusaahan tersebut merupakan perusahaan retail besar di Indonesia yang selalu menuntutnya untuk terus berkembang dengan sistem yang semakin canggih di era globalisasi ini agar tidak kalah bersaing dengan perusahaan lain.

\section{Tujuan Penelitian}

Tujuan penelitian yang ingin dicapai dalam penelitian ini adalah sebagai berikut :

1. Untuk mengetahui pengaruh secara bersama dukungan manajemen dan pengetahuan manajer terhadap efektivitas sistem informasi akuntansi

2. Untuk mengetahui pengaruh dukungan manajemen puncak terhadap efektivitas sistem informasi akuntansi

3. Untuk mengetahaui pengaruh pengetahuan manajer terhadap efektivitas sistem informasi akuntansi

\section{TINJAUAN PUSTAKA}

\section{Pengertian Akuntansi}

Akuntansi sebagai proses pengidentifikasian, pengukur dan pelaporan informasi ekonomi untuk memungkinkan adanya penilaian-penilaian dan keputusan yang jelas dan tegas bagi mereka yang menggunakan informasi tersebut (The dan Sugiono, 2015:2)

\section{Sistem Informasi Akuntansi (SIA)}

Sistem informasi akuntansi merupakan sistem yang menyediakan informasi akuntansi dan keuangan beserta informasi lainnya yang diperoleh dari proses rutin transaksi akuntansi (TMBooks, $2014:$ 2)

\section{Dukungan Manajemen Puncak}

Dukungan manajemen puncak adalah kegiatan yang berdampak, mengarahkan dan menjaga perilaku manusia yang ditunjukkan oleh direktur, presiden, kepala divisi dan sebagainya dalam organisasi (Sang Ayu Nyoman Trisna Dewi \& AANB Dwirandra, 2013)

\section{Pengetahuan Manajer}

Tuomi (1999) dikutip dalam Ismail Nawawi, 2012:3 pengetahuan manajemen dalam kajian ilmiah bukan suatu disiplin pengetahuan tetapi merupakan persoalan.

Menurut Budihardjo (2016: 180) secara umum ada 2 dimensi pengetahuan yaitu tacit knowledge dan explicit knowledge. Pengetahuan tacit adalah pengetahuan yang dimiliki oleh 
seseorang namun sulit diungkapkan atau di artikulasikan. Pengetahun explicit adalah jenis pengetahuan yang konkret, biasanya diungkapkan dalam bentuk bahasa (kata-kata, angka, simbol-simbol lain), mudah ditransfer pada orang lain.

\section{Efektivitas Sistem Informasi Akuntansi}

Tjhai Fung Jen (2002) menyebutkan mengukur efektivitas SIA dari dua pendekatan yaitu kepuasan pemakai SIA dan pemakaian SIA itu sendiri oleh karyawan

\section{Hipotesis}

H1 = Dukungan Manajemen Puncak dan Pengetahuan Manajer berpengaruh terhadap Efektivitas Sistem Informasi Akuntansi

H2 = Dukungan Manajemen Puncak berpengaruh terhadap Efektivitas Sistem Informasi Akuntansi

H3 = Pengetahuan Manajer berpengaruh terhadap Efektivitas Sistem Informasi Akuntansi

\section{Penelitian Terdahulu}

1. Penelitian yang dilakukan oleh Purnomo (2014) menunjukkan dukungan manajemen puncak dan pengetahuan manajer berpengaruh positif terhadap efektivitas sistem informasi akuntansi

2. Penelitian yang dilakukan oleh Luh Nanda Yogita Fani,Nyoman Ari Surya Darmawan \& I Gusti Ayu Purnamawati (2015) menunjukkan dukungan manejemen puncak berpengaruh terhadap efektivitas sistem informasi akuntansi

3. Penelitian yang dilakukan oleh Ni Luh Candra Pradani, Edy Sujana, I Gusti Ayu Purnamawati (2017) menunjukkan pengetahuan manajer berpengaruh terhadap efektivitas sistem informasi akuntansi

4. Penelitian yang dilakukan oleh Biwi (2015), menunjukkan bahwa dukungan manajemen puncak berpengaruh signifikan terhadap kinerja sistem informasi akuntansi

\section{METODE PENELITIAN}

\section{Jenis Penelitian}

Penelitian ini merupakan penelitian asosiatif. Penelitian asosiatif merupakan penelitian yang bertujuan untuk mengetahui hubungan antara dua variabel atau lebih serta mengetahui pengaruhnya (Sujarweni, 2014: 11). Dalam penelitian ini bertujuan untuk mengetahui Pengaruh Dukungan Manajemen Puncak dan Pengetahuan Manajer terhadap Efektivitas Sistem Informasi Akuntansi.

\section{Tempat dan Waktu Penelitian}

Penelitian ini dilakukan pada perusahaan retail yang berada di Kota Manado diwakili oleh PT. Ace Hardware Tbk (Manado Town Square, Jl. Piere Tendean Boulevard), PT. Informa Furnishings (Manado Town Square, Jl. Piere Tendean Boulevard) dan Toys Kingdom (Manado Town Square, Jl. Piere Tendean Boulevard) . Penelitian ini dilakukan pada bulan Mei 2017.

\section{Populasi dan Sampel}

Populasi dalam penelitian ini adalah perusahaan retail di Manado. Dalam hal ini diwakili oleh tiga perusahaan retail yang berada di Manado yaitu PT.Ace Hardware Tbk, PT. Informa Furnishings dan Toys Kingdom.

Teknik pengambilan sampel dalam penelitian ini berupa purposive sampling.Sampel dalam penelitian ini adalah karywan pemakai sistem informasi akuntansi sebanyak 45 orang. 
Adapun kriteria dalam penelitian ini difokuskan hanya karyawan yang menggunakan sistem informasi akuntansi pada perusahaan. Karyawan tersebut tersebar sesuai jobdesk-nya masingmasing yaitu untuk bagian finance, accounting, tax, IT, dan SDM ada di dalam berbagai bidang struktur organisasi perusahaan.

\section{Jenis dan Sumber Data}

Penelitian ini menggunakan metode analisis data kuantitatif yaitu menggunakan rumus-rumus statisktik yang disesuaikan judul penelitian dan rumusan masalah, untuk perhitungan angka-angka dalam rangka menganalisis data yang diperoleh dari pihak karyawan pemakai sistem informasi akuntansi pada perusahaan retail di Manado. Sumber data yang digunakan dalam penelitan ini yaitu data primer yang diperoleh secara langsung melalui pembagian kuesioner pada karyawan pemakai sistem informasi akuntansi pada perusahaan tiga retail di Manado.

\section{Teknik Pengumpulan Data}

Teknik pengumpulan data yang dilakukan adalah dengan menggunakan metode kuesioner tipe tertutup yakni berisi pernyataan yang mengharapkan responden untuk memilih salah satu alternative jawaban dari setiap pernyataan yang telah tersedia (Sugiyono, 2013: 142-143). Dalam hal ini peneliti melakukan pembagian kuesioner untuk pihak karywan pemakai sistem informasi akuntansi pada tiga perusahaan retail di Manado.

\section{Definisi dan Pengukuran Variabel Operasional}

$\mathrm{Y} \quad=$ Efektivitas Sistem Informasi Akuntansi, variabel ini diukur dengan skala likert.

$\mathrm{X}_{1} \quad=$ Dukungan Manajemen Puncak, variabel ini diukur dengan skala likert.

$\mathrm{X}_{2} \quad=$ Pengetahuan Manajer, variabel ini diukur dengan skala likert.

\section{Metode Analisis}

Metode yang digunakan untuk menganalisis data instrumen penelitian berupa kuesioner adalah uji kualitas data dengan melakukan uji validitas dan uji reliabilitas. Selanjutnya agar hasil perhitungan dapat diinterprestasikan dengan akurat dilakukan uji asumsi klasik yang meliputi uji normalitas, uji multikolonieritas dan uji heteroskedastisitas. Terakhir, dilakukan pengujian terhadap model regresi linear berganda yang meliputi uji koefisien determinasi $\left(\mathrm{R}^{2}\right.$ ), uji signifikan simultan (uji $\mathrm{F}$ ), dan uji signifikan parameter individual (uji t). Semua uji analisis ini dilakukan dengan bantuan software SPSS Statistic versi 22.

\section{HASIL PENELITIAN DAN PEMBAHASAN Gambaran Umum Objek Penelitian \\ Profil Perusahaan PT. Ace Hardware Tbk}

Didirikan pada tahun 1995 sebagai anak perusahaan dari PT. Kawan Lama Sejahtera - pusat perlengkapan teknik dan industri \#1 di Indonesia, PT. Ace Hardware Indonesia, Tbk. ialah pemegang lisensi tunggal ACE Hardware di negeri ini, yang ditunjuk secara langsung oleh ACE Hardware Corporation, Amerika.

\section{Profil Perusahaan PT. Informa Furnishings}

Pada tahun 1995-1996, dengan semakin banyaknya produk yang dipasarkan dan agar lebih fokus melayani dan memenuhi kebutuhan pelanggan, maka diluncurkan kebijakan membangun "Grup Kawan Lama". Sejumlah anak perusahaan Kawan Lama yang didirikan antara lain PT Informa Furnishings (dahulu Index Furnishings. 
INFORMA adalah ritel furnishings terbesar dan terlengkap di Indonesia. Menyediakan lebih dari 60.000 produk-produk berkualitas dengan suasana belanja yang menyenangkan.

\section{Profil Perusahaan Toys Kingdom}

Pada tahun 1995-1996, dengan semakin banyaknya produk yang dipasarkan dan agar lebih fokus melayani dan memenuhi kebutuhan pelanggan, maka diluncurkan kebijakan membangun "Grup Kawan Lama". Sejumlah anak perusahaan Kawan Lama yang didirikan antara lain Toys Kingdom. Toys Kingdom merupakan gerai mainan anak-anak yang dikelola oleh anak usaha ACES yaitu PT Toys Games Indonesia. Sebagian besar mainan di Toys Kingdom merupakan mainan bermerek internasional, dengan produknya antara lain mainan edukatif, outdoor, perempuan, laki-laki, bayi, dan binatang.

\section{Hasil Penelitian}

Dalam penelitian ini responden yang digunakan adalah karyawan bagian akuntansi, IT dan SDM keuangan, pada PT. Ace Hardware Tbk Manado mengambil sampel sebanyak 18 responden , PT. Informa Furnishings Manado mengambil sampel sebanyak 17 responden dan PT. Toys Kingdom Manado dengan mengambil sampel 10 responden dengan total pembagian kuesioner pada 45 karyawan.

Penyebaran kuesioner dilakukan pada tanggal 22 Mei 2017 sampai dengan tanggal 29 Mei 2017. Dari jumlah 45 kuesioner yang dibagikan, jumlah kuesioner yang dikembalikan adalah sebanyak 42 .

\section{Uji Kualitas Data}

Untuk melihat apakah data yang diperoleh dari kuesioner yang dibagikan dapat dipercaya dilakukan uji validitas dan uji reliabilitas. Penelitian ini telah lulus uji validitas dan uji reliabilitas.

\section{Uji Asumsi Klasik}

Agar hasil penelitian dapat diinterprestasikan dengan akurat maka dilakukan uji asumsi klasik. Penelitian ini telah lulus uji normalitas, multikolinieritas serta heterokedastisitas.

\section{Uji Hipotesis}

\section{Uji Koefisien Determinasi $\left(\mathbf{R}^{2}\right)$}

Tabel 4.14 Hasil Uji Koefisien Determinasi $\left(\mathbf{R}^{2}\right)$ Model Summary ${ }^{\text {b }}$

\begin{tabular}{ccccc}
\hline Model & $\mathrm{R}$ & R Square & $\begin{array}{c}\text { Adjusted } \mathrm{R} \\
\text { Square }\end{array}$ & $\begin{array}{c}\text { Std. Error of the } \\
\text { Estimate }\end{array}$ \\
\hline 1 &, $505^{\mathrm{a}}$ &, 255 &, 216 & 3,24689 \\
\hline
\end{tabular}

a. Predictors: (Constant), Pengetahuan Manajer, Dukungan Manajemen Puncak

\section{b. Dependent Variable: Efektivitas SIA}

Sumber : Data Primer yang Diolah (2017)

Hasil menunjukkan nilai Adjusted R Square sebesar 0,216 atau sebesar 21,6\%. Hal itu menunjukkan bahwa kedua variabel Independen yaitu Dukungan Manajemen Puncak dan Pengetahuan Manajer berpengaruh sebesar 21,6\% terhadap Efektivitas Sistem Informasi Akuntansi. Sementara itu sebesar 78,4\% (100\% - 21,6\%) lainnya dijelaskan oleh variabel 
lain diluar variabel independen yang digunakan.

\begin{tabular}{|c|c|c|c|c|c|c|}
\hline \multicolumn{7}{|c|}{$\begin{array}{c}\text { Uji Signifikan Simultan (Uji F) } \\
\text { ANOVA }^{\mathrm{a}}\end{array}$} \\
\hline & Model & $\begin{array}{l}\text { Sum of } \\
\text { Squares }\end{array}$ & df & Mean Square & $\mathrm{F}$ & Sig. \\
\hline \multirow[t]{3}{*}{1} & Regression & 140,469 & 2 & 70,234 & 6,662 &, $003^{b}$ \\
\hline & Residual & 411,150 & 39 & 10,542 & & \\
\hline & Total & 551,619 & 41 & & & \\
\hline
\end{tabular}

a. Dependent Variable: Efektivitas SIA

b. Predictors: (Constant), Pengetahuan Manajer, Dukungan Manajemen Puncak Sumber: Data Primer yang Diolah (2017)

\section{H1 : Dukungan Manajemen Puncak dan Pengetahuan Manajer berpengaruh terhadap Efektivitas Sistem Informasi Akuntansi}

Hasil perbandingan antara $\mathrm{F}$ hitung dan $\mathrm{F}$ tabel yaitu $\mathrm{F}$ hitung $=6,662>\mathrm{F}$ tabel $=3,23$ dengan tingkat signifikan $0,003<0,05$. Maka dapat disimpulkan bahwa seluruh variabel independen yaitu Dukungan Manajemen Puncak dan Pengetahuan Manajer secara bersamasama mempengaruhi variabel dependen Efektivitas Sistem Informasi Akuntansi secara positif. Maka H1 diterima.

\section{Coefficients $^{\mathrm{a}}$}

\begin{tabular}{|c|c|c|c|c|c|c|}
\hline \multirow{5}{*}{1} & \multirow{3}{*}{$\begin{array}{l}\text { Model } \\
\quad \text { (Constant) }\end{array}$} & \multicolumn{2}{|c|}{$\begin{array}{l}\text { Unstandardized } \\
\text { Coefficients }\end{array}$} & \multirow{3}{*}{$\begin{array}{c}\begin{array}{c}\text { Standardized } \\
\text { Coefficients }\end{array} \\
\text { Beta }\end{array}$} & \multirow{3}{*}{$\begin{array}{l}\mathrm{t} \\
6,620\end{array}$} & \multirow{3}{*}{$\begin{array}{l}\text { Sig. } \\
\quad, 000\end{array}$} \\
\hline & & $\mathrm{B}$ & Std. Error & & & \\
\hline & & 28,992 & 4,380 & & & \\
\hline & Dukungan & ,353 & ,098 & ,498 & 3,594 &, 001 \\
\hline & Pengetahuan & 103 & 247 & 058 &, 418 & 678 \\
\hline
\end{tabular}

a. Dependent Variable: Efektivitas

Sumber: Data Primer yang Diolah (2017)

\section{H2 : Dukungan Manajamen Puncak Berpengaruh Terhadap Efektivitas Sistem Informasi Akuntansi}

Variabel Dukungan Manajemen Puncak menunjukkan nlai thitung sebesar 3,594 > t tabel $(2,023)$ dan nilai signifikan $0,001<0,05$. Hal ini menunjukkan bahwa secara individu atau parsial Dukungan Manajemen Puncak berpengaruh signifikan positif terhadap Efektivitas Sistem Informasi Akuntansi. Maka H2 diterima

\section{H3 : Pengetahuan Manajer Berpengaruh Terhadap Efektivitas Sistem Informasi Akuntansi}

Variabel Pengetahuan Manajer menunjukkan nilai t hitung sebesar 0,418 yang berarti $<\mathrm{t}$ tabel $(2,023)$ dan nilai signifikan 0,678>0,05. Hal ini menunjukkan bahwa secara individual atau parsial Pengetahuan Manajer tidak berpengaruh terhadap Efektivitas Sistem Informasi Akuntansi. Maka H3 ditolak

Berdasarkan tabel persamaan regresi linear berganda dapat ditulis sebagai berikut:

$$
\begin{gathered}
\mathrm{Y}=\alpha+\beta_{1} \mathrm{X}_{1}+\beta_{2} \mathrm{X}_{2}+\mathrm{e} \\
\mathrm{Y}=28,992+0,353 \mathrm{X}_{1}+0,103 \mathrm{X}_{2}
\end{gathered}
$$




$\begin{array}{ll}\text { Dimana: } & \\ \mathrm{Y} & =\text { Efektivitas Sistem Informasi Akuntansi } \\ & =\text { Konstanta } \\ \mathrm{X} 1 & =\text { Dukungan Manajemen Puncak } \\ \mathrm{X} 2 & =\text { Pengetahuan Manajer } \\ \beta 1 \beta 2 \beta 3 & =\text { Koefisien regresi } \\ \mathrm{e} & =\text { Standar error }\end{array}$

\section{Pembahasan}

\section{Pengaruh Dukungan Manajemen Puncak dan Pengetahuan Manajer Terhadap Efektivitas Sistem Informasi Akuntansi}

Berdasarkan uji simultan yang di dapat menunjukkan bahwa Dukungan Manajemen Puncak (X1) dan Pengetahuan Manajer (X2) secara bersama-sama mempunyai pengaruh terhadap Efektivitas Sistem Informasi Akuntansi (Y) dengan nilai F hitung sebesar 6,620 > F tabel 3,23 dan nilai signifikan $0,000<0,05$. Hasil penelitian ini mendukung hasil penelitian Purnomo (2014) yang menyatakan bahwa Dukungan Manajemen Puncak dan Pengetahuan Manajer secara bersama-sama berpengaruh terhadap Efektivitas Sistem Informasi Akuntansi.

Dalam penelitian ini menunjukkan bahwa dukungan manajemen puncak dan pengetahuan manajer berpengaruh terhadap efektivitas sistem informasi akuntansi. Hal ini berarti semakin tingginya dukungan manajemen puncak dan pengetahuan manajer dapat meningkatkan efektivitas sistem informasi akuntansi dalam perusahaan.

\section{Pengaruh Dukungan Manajemen Puncak Terhadap Efektivitas Sistem Informasi Akuntansi}

Berdasarkan hasil uji parsial yang didapat, variabel Dukungan Manajemen Puncak (X1) berpengaruh positif terhadap Efektivitas Sistem Informasi Akuntansi (Y) dengan nilai t hitung sebesar 3,594 > t tabel 2,023 dan nilai signifikan sebesar 0,001<0,05. Dengan demikian maka ditunjukkan bahwa secara parsial Dukungan Manajemen Puncak memiliki pengaruh positif terhadap Efektivitas Sistem Informasi Akuntansi.

Hasil penelitian ini mendukung hasil penelitian sebelumnya yang dilakukan oleh Luh Nanda Yogita Fani,Nyoman Ari Surya Darmawan \& I Gusti Ayu Purnamawati (2015) yang dalam penelitiannya menyatakan bahwa terdapat pengaruh dari Dukungan Manajemen Puncak terhadap Efektivitas Sistem Informasi Akuntansi.

Dukungan manajemen puncak merupakan faktor penting dalam menentukan efektivitas penerimaan sistem informasi dalam sebuah perusahaan. Dukungan yang diberikan manajemen puncak dalam pengembangan atau penggunaan sistem informasi akuntansi yang dilakukan oleh bawahan/karyawan dapat meningkatkan efektivitas sistem informasi akuntansi perusahaan dikarenakan adanya hubungan positif antara manajemen puncak dan karyawan pemakai sistem informasi akuntansi.

\section{Pengaruh Pengetahuan Manajer Terhadap Efektivitas Sistem Informasi Akuntansi}

Berdasarkan uji parsial yang di dapat menunjukkan bahwa Pengetahuan Manajer (X2) tidak berpengaruh terhadap Efektivitas Sistem Informasi Akuntansi (Y) dengan nilai t hitung $0,418<\mathrm{t}$ tabel 2,023 dan nilai signifikan 0,678>0,05. Dalam hal ini pengetahuan manajer sangat dibutuhkan untuk meningkatkan efektivitas sistem informasi akuntansi. Adanya pengalaman dan pengetahuan yang lebih baik tentang sistem informasi akuntansi (SIA), serta dapat membantu karyawan yang sulit dalam menjalankan SIA yang digunakan perusahaan, dengan adanya interaksi positif antara manajer dan karyawan pemakai SIA dapat meningkatkan efektivitas SIA dalam perusahaan tersebut. Namun dalam hal ini pihak 
karyawan dan manajer masih kurang dalam menjalin komunikasi dan terbuka tentang kesulitan dalam pemakaian SIA yang diterapkan perusahaan.

\section{PENUTUP}

\section{Kesimpulan}

Berdasarkan hasil analisis dan pembahasan mengenai pengaruh Dukungan Manajemen Puncak dan Pengetahuan Manajer terhadap Efektivitas Sistem Informasi Akuntansi pada Perusahaan Retail di Manado, maka dapat ditarik kesimpulan sebagai berikut:

1. Hasil penelitian ini menunjukkan bahwa Dukungan Manajemen Puncak dan Pengetahuan Manajer secara bersama berpengaruh terhadap Efektivitas Sistem Informasi Akuntansi

2. Hasil penelitian ini menunjukkan bahwa dukungan manajemen puncak berpengaruh positif terhadap efektivitas sistem informasi akuntansi

3. Hasil penelitian ini menunjukkan bahwa pengetahuan manajer tidak berpengaruh terhadap efektivitas sistem informasi akuntansi

\section{Saran}

Dengan memperhatikan hasil analisis dan kesimpulan maka saran yang dapat diberikan adalah sebagai berikut:

1. Bagi perusahaan dengan adanya penelitian ini diharapkan perusahaan selalu menjalin komunikasi yang positif antara pihak manajer dan karyawan demi meningkatkan efektivitas sistem informasi akuntansi dan manajer lebih banyak lagi mempelajari tentang sistem yang diterapkan perusahaan, sehingga pengetahuan tentang sistem informasi akuntansi lebih luas dan dapat meningkatkan efektivitas sistem informasi akuntansi pada perusahaan .

2. Bagi peneliti selanjutnya perbanyak variabel yang digunakan untuk mengukur efektivitas sistem informasi akuntansi dan perbanyak sampel yang digunakan agar hasil yang didapat lebih efektif.

\section{DAFTAR PUSTAKA}

Arzia Biwi, Ananta Wikrama Tungga Atmaja dan Nyoman Ari Surya Darmawan. (2015) Pengaruh Kapabilitas Personal dan Dukungan Manajemen Puncak Terhadap Kinerja Sistem Informasi Akuntansi PT Tirta Mumbul Jaya Abadi Singaraja. Ejournal S1 Akuntansi Unversitas Pendidikan Ganesha, Vol. 3, No. 1.

Budihardjo, A. (2016). Knowledge Management. Jakarta: Prasetiya Mulya Publishing.

Fadhilah, B.N. (2013). Pengaruh Komitmen Organisasi dan Pengetahuan Manajer Terhadap Keberhasilan Penerapan Sistem Informasi Akuntansi. Jurnal dan Riset Akuntansi, Vol 2 No 6.

Fatimah. (2013). Pengaruh Pelatihan Dukungan Manajemen Puncak dan Kejelasan Tujuan Terhadap Efektivitas Sistem Informasi Akuntansi Keuangan Daerah. E-Jurnal Akuntansi dan Keuangan Universitas Padang, Vol.1, No.1.

Ishak The dan Arief Sugiono. (2015). Akuntansi: Informasi Dalam Mengambil Keputusan. Jakarta: PT Grasindo.

Jen, T.F. (2002). Faktor-Faktor yang Mempengaruhi Sistem Informasi Akuntansi. JurnalBisnis dan Akuntansi, Vol IV Nomor 2.

Luh Nanda Yogita Fani,Nyoman Ari Surya Darmawan \& I Gusti Ayu Purnamawati. (2015). Pengaruh Kecanggihan Teknologi Informasi, Kemampuan Teknik Pemakai dan Dukungan Manajemen Puncak Terhadap Kinerja Sistem Informasi (Studi Empiris Pada PT PLN (Persero) Area Bali Utara Kantor Pusat). e-Journal S1 Ak Universitas Pendidikan Ganesha, Vol 3 No 1. 
Nawawi, I. (2012). Manajemen Pengetahuan (Knowledge Management). Bogor: Ghalia Indonesia

Ni Luh Candra Pradani, Edy Sujana, I Gusti Ayu Purnamawati. (2017). Pengaruh Kecanggihan Teknologi Informasi, Perlindungan Sistem Informasi, Partisipasi Manajemen dan Pengetahuan Manajer Akuntansi Terhadap Efektivitas Sistem Informasi Akuntansi Pada Hotel Berbintang di Kabupaten Karangasem. E-journal S1 Ak Universitas Pendidikan Ganesha, Vol 7 No 1.

Purnomo, T. (2014). Pengaruh Dukungan Manajemen Puncak Dan Pengetahuan Manajer Terhadap Efektivitas Sistem Informasi Akuntansi (Studi Kasus Pada PT. Jasa Marga (PERSERO), tbk Cabang Purbaleunyi.

Ratnaningsih Kadek Indah dan I Gusti Ngurah Agung Suaryana. (2014). Pengaruh Kecanggihan Teknologi Informasi, Partisipasi Manajemen, Dan Pengetahuan Manajer Akuntansi Pada Efektivitas Sistem Informasi Akuntansi. E-Jurnal Akuntansi Universitas Udayan, Vol 6 No 1.

Sang Ayu Nyoman Trisna Dewi \& AANB Dwirandra. (2013). Pengaruh Dukungan Manajemen Puncak, Kualitas Sistem, Kualitas Informasi, Pengguna Aktual Dan Kepuasan Pengguna Terhadap Implementasi Keuangan Daerah Di Kota Denpasar. EJurnal Akuntansi Universitas Udayana, Vol 4 No 1.

Sugiyono. 2013. Metode Penelitian Pendidikan (Pendekatan Kuantitatif, Kualitatif, dan $R \& D)$. Bandung: Alfabeta.

Sujarweni, V. W. 2014. Metode Penelitian. Yogyakarta: PUSTAKA BARU PRESS.

TMBooks. (2015). Sistem Informasi Akuntansi Konsep dan Penerapan. Yogyakarta: ANDI. 